
\section{International Scientific Journal Theoretical \& Applied Science}

p-ISSN: 2308-4944 (print) e-ISSN: 2409-0085 (online)

Year: 2017 Issue: 09 Volume: 53

Published: $26.09 .2017 \quad$ http://T-Science.org
Kristina Georgievna Korovina student of Accounting and Finance Faculty

Kuban State Agrarian University named after I. T. Trubilin, Krasnodar, Russia

Vasiliy Evgenievich Polyakov associate professor, department of Economic analysis

Kuban State Agrarian University named after I. T. Trubilin, Krasnodar, Russia

SECTION 31. Economic research, finance, innovation, risk management.

\title{
ECONOMIC ANALYSIS OF HOUSING AND MORTGAGE LENDING MARKETS
}

Abstract: Reduction of real incomes of the population in combination with the growth of housing prices led to a decrease in the area of housing in the Krasnodar region. To stabilize the situation in the housing market, interest rates on mortgage lending were significantly reduced. The analysis showed that this is a temporary half-measure, which does not solve the problems on the market. The main conditions of improving the situation in the housing market have been determined and an analysis of the obstacles to their implementation has been carried out.

Key words: analysis, market, realty, housing construction, mortgage lending, interest rate, overdue debt, monthly payment, income, costs, Microsoft Excel.

Language: Russian

Citation: Korovina KG, Polyakov VE (2017) ECONOMIC ANALYSIS OF HOUSING AND MORTGAGE LENDING MARKETS. ISJ Theoretical \& Applied Science, 09 (53): 140-146.

Soi: $\underline{\text { http://s-o-i.org/1.1/TAS-09-53-21 Doi: crossef https://dx.doi.org/10.15863/TAS.2017.09.53.21 }}$

\section{ЭКОНОМИЧЕСКИЙ АНАЛИЗ РЫНКОВ ЖИЛЬЯ И ИПОТЕЧНОГО КРЕДИТОВАНИЯ}

Аннотация: Снижение реальных денежных доходов населения в сочетании с ростом иен на недвижимость привело к уменьшению объемов вводимого жилья в Краснодарском крае. Для стабилизаиии положения на рынке недвижимости были существенно снижены процентные ставки по ипотечному кредитованию. Проведенный анализ показал, что это временная полумера, которая не решает имеющихся на рынке проблем. Определены основные условия улучшения ситуации на рынке жилья и проведен анализ препятствий к их реализации.

Ключевые слова: анализ, рынок, недвижимость, жилищное строительство, ипотечное кредитование, прочентная ставка, просроченная задолженность, ежемесячный платеж, доходы, pacxoды, Microsoft Excel.

\section{Introduction}

Экономика России на современном этапе переживает не лучшие времена. Не успели преодолеть последствия мирового финансового кризиса, как положение усложнили экономические санкции западных стран, которые в условиях сильной импортозависимости России оказали негативное влияние на динамику ее экономического развития. Происходящее в результате снижение денежных доходов отразилось на способности населения к улучшению жилищных условий. А продолжающийся рост цен на рынке жилья лишь усугубил ситуацию.

Materials and Methods

По данным Министерства экономики
Краснодарского края в 2016 г. реальные располагаемые денежные доходы населения снизились на $2,4 \%$, а реальная заработная плата вследствие опережающего роста инфляции $(107,1$ $\%$ ) снизилась на 0,2 \% по сравнению с уровнем 2015 г. [1]. При этом за первое полугодие 2017 г. реальные денежные доходы населения снизились на 3,2 \% к аналогичному периоду предыдущего года, а реальная заработная плата выросла на $1,4 \%$ в условиях роста потребительских цен на $4,9 \%$ [2].

Следует отметить, что на фоне общероссийских показателей эта динамика выглядит довольно оптимистично - реальные доходы населения России снизились на $5 \%$.

За этот же период времени цены за квадратный метр на рынке квартир

ISPC Innovations in science, 
Краснодарского края выросли на 2 - $4 \%$.

Очевидно, что снижение доходов населения и рост цен на недвижимость приводят к замедлению развития рынка жилья.

Уменьшение объемов вводимого жилья в Краснодарском крае прослеживается на протяжении последних трех лет. Так, по данным Краснодарстата [4], ввод квартир в 2014 г. составил 4777,7 тыс. кв. м., в 2015 г. - 4623,4 тыс. кв. м., в 2016 г. $-4474,5$ тыс. кв. м. (рисунок 1).

В докладах Министерства экономики Краснодарского края «Об итогах социальноэкономического развития Краснодарского края» в первом квартале и первом полугодии 2017 года отмечается, что продолжается снижение количества зданий жилого назначения. При этом в качестве причины указывается сокращение реальных доходов населения и отказ от приобретения товаров длительного пользования, в первую очередь, жилья [2, 3].

В первом полугодии 2017 г. в
Краснодарском крае введено 5707 зданий жилого назначения, что на 1144 зданий меньше, чем за аналогичный период 2016 г. Площадь введенного жилья уменьшилась на $3,8 \%$, хотя и построено при этом 2042,2 тыс. кв. м. Объемы индивидуального строительства снизились на $7 \%$ (до 792 тыс. кв. м), многоквартирного жилья - на $1,6 \%$ (до 1250,3 тыс. кв. м.).

Доля индивидуальных застройщиков в общем объеме всего введенного жилья снизилась до $38,8 \%$ (против 40,1 \% год назад).

На основании динамики за 2014 - 2016 гг. и данных за 1 полугодие 2017 г. нами составлен прогноз объема вводимых квартир до конца 2017 г. (рисунок 1). Он составил 4322 тыс. кв. м.

При этом положение на рынке жилья в Краснодарском крае еще довольно благоприятно. Для сравнения: в среднем по России за 1 полугодие 2017 года объем ввода жилья снизился на $11,3 \%$, а в Южном федеральном округе - на $6,6 \%$.

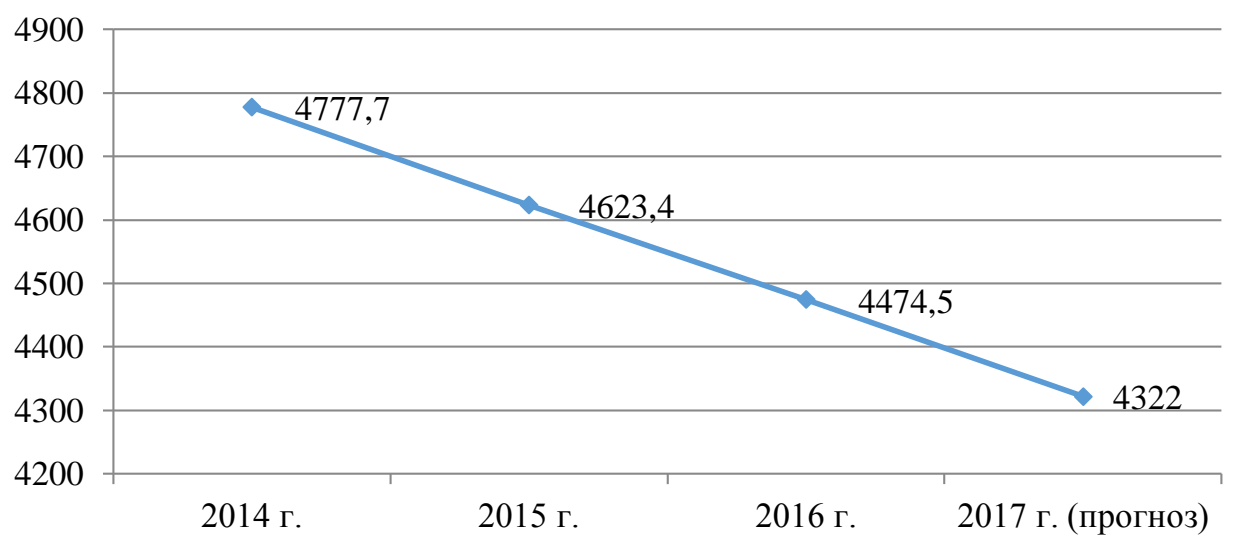

$\multimap$ Ввод в действие квартир, тыс. кв. м.

Рисунок 1 - Ввод в действие квартир в Краснодарском крае в 2014 - 2017 гг., тыс. кв. м.

Снижение текущей платежеспособности населения вследствие уменьшения реальных денежных доходов способствует росту интереса к покупке жилья в кредит. Очевидно, что в сложившейся ситуации одним из наиболее доступных способов приобретения жилья является ипотечное кредитование.

Вышеуказанные факторы, несмотря на завершение программы государственной поддержки ипотечного кредитования в марте 2017 г., привели к росту объемов данного вида кредитов. Так, по данным Агентства ипотечного жилищного кредитования за первое полугодие 2017 г. в Краснодарском крае выдано 20 млрд руб. ипотечных кредитов [5] (8 место по России), что на 22,3 \% больше, чем за 2016 г. Доля ипотечных кредитов, выданных на приобретение строящегося жилья, составила $43 \%$. В банке «Кубань Кредит» (единственном банке
Краснодарского края, входящем в топ-30), ипотечное кредитование за первое полугодие 2017 г. выросло на 45 \%, а объем выданных кредитов превысил 1,7 млрд рублей.

Необходимость стимулирования рынка жилья, угроза уменьшения финансовых результатов деятельности банков в случае снижения объемов ипотечного кредитования вследствие уменьшения реальных денежных доходов населения привели к заметному снижению ставок по ипотечному кредитованию. Если бы банки не снизили ставки, то количество покупателей жилья резко уменьшилось, что в свою очередь привело к снижению продаж, как на первичном, так и на вторичном рынках.

По данным Агентства ипотечного кредитования в 1 полугодии 2017 г. ставки по ипотеке снизились на 0,6 \% и составили $10,7 \%$ на новостройки (первичный рынок) и 11,3\% на 
готовое жилье (вторичный рынок) [5].

В третьем квартале 2017 г. эта тенденция продолжилась. Ведущие банки снизили ставки до $10,1 \%$ на первичном рынке жилья и $10,6 \%$ на вторичном рынке (рисунок 2). В августе-сентябре 2017 г. получить ипотеку можно уже по ставкам от $9,5 \%$ [6].

Снижение ставок по ипотечным кредитам, безусловно, стимулирует рост объемов кредитования и увеличение продаж на рынке жилья. Однако также очевидно, что это временная мера, которая не решает, а лишь служит отсрочкой решения сложившихся на рынке жилья проблем.

Возможности банков по дальнейшему снижению процентной ставки по ипотечному кредитованию ограничены ключевой ставкой ЦБ РФ, которая с 18 сентября 2017 г. составляет 8,5\% и за прошедший год (с 19 сентября 2016 г.) уже была снижена на $1,5 \%$. Весьма маловероятно, что банки снизят ставки по ипотечному кредитованию ниже уровня ключевой ставки ЦБ РФ, хотя у них и имеются иные, помимо кредитов Центрального банка, более «дешевые» возможности по привлечению денежных средств.

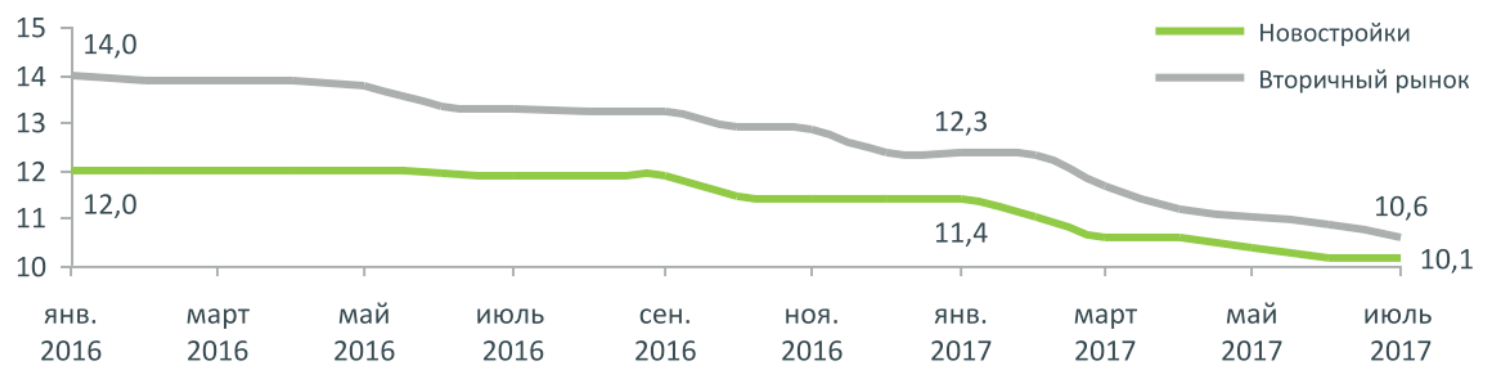

по данным Агентства ипотечного жилищного кредитования

\section{Рисунок 2 - Средневзвешенные процентные ставки по ипотечным кредитам, \% [5]}

Таким образом, максимальный «резерв» снижения процентной ставки по ипотеке составляет еще $1,6 \%(10,1-8,5)$ при условии сохранения ключевой ставки ЦБ РФ на текущем уровне (а дальнейшее ее снижение в ближайшее время также весьма маловероятно). Конечно, остаются еще различные дополнительные условия ипотечного кредитования (например, отмена или снижение первоначального взноса), которыми банки могут регулировать развитие данного продукта, однако они не велики.

Кроме того, нельзя игнорировать тот факт, что, несмотря на снижение процентной ставки по ипотечным кредитам, уменьшение реальных доходов населения приводит к появлению просроченной задолженности и росту неплатежей. Так, по данным аналитиков Национального бюро кредитных историй в Краснодарском крае за январь-апрель 2017 г. доля просроченных ипотечных кредитов в сравнении с 4 кварталом 2016 г. выросла с 4,1\% до 4,3\%. Краснодарский край занял третье место в России по темпам роста просроченной задолженности по ипотечным кредитам [7].

Следует отметить, что в сравнении с другими видами кредитов доля просроченной задолженности по ипотеке невелика, хотя ее рост и вызывает настороженность. Например, доля просроченной задолженности по потребительским кредитам за то же время выросла с 24,6 до 25,2 \% (11 место в РФ).
Снижение процентной ставки по ипотеке, которое, вероятно, продолжится, на некоторое время стабилизирует ситуацию на рынке недвижимости. Однако если существующее положение в российской экономике сохранится, то выигранный временной резерв будет довольно незначительным.

Проиллюстрируем данное утверждение на следующем примере.

Из доклада Министерства экономики Краснодарского края «Об итогах социальноэкономического развития Краснодарского края в первом полугодии 2017 года» следует, что средние денежные доходы трудоспособного населения составили 29874 руб. в месяц. Из них $60,6 \%$ расходуется населением на покупку, $22,3 \%$ - на оплату услуг, 8,4 \% - на оплату обязательных платежей и взносов. Доля доходов, направляемых на сбережения, снизилась с $11,7 \%$ до $6,1 \%$ [2].

По данным сайта RLT24 средняя цена однокомнатной квартиры в Краснодаре в сентябре 2017 г. составила 1976563 руб. [8]. Процентная ставка по ипотеке, предлагаемая большинством банков Краснодара (ВТБ, Уралсиб), - 10 \% при условии первоначального вноса не менее $10 \%$. По данным РБК Юг средний срок ипотечного кредита в 1 полугодии 2017 г. вырос на шесть месяцев и по данным на 1 июля 2017 г. составил 15,5 лет [9].

На основе этих данных рассчитаем сумму 
ежемесячного платежа, который необходимо будет уплатить, если взять ипотечный кредит:

1) в сумме 1800000 руб. (стоимость однокомнатной квартиры - 2 млн руб. за вычетом первоначального взноса в размере $10 \%$ );

2) по ставке $10 \%$ годовых;

3) на срок 15 лет.

Для расчета воспользуемся финансовой функцией ПЛТ Microsoft Excel, которая служит для определения размера периодического разового платежа финансовой ренты, в качестве которого может выступать ежемесячный платеж по кредиту [10]. Заполним исходные данные как указано на рисунке 3.
В аргументе Ставка указан расчет процентной ставки за месяц: 0,83 \% (10 \% / 12 месяцев), т. к. погашение кредита предусматривается равными ежемесячными выплатами. В аргументе Кпер указано количество периодов погашения кредита - 15 лет по 12 месяцев: 180 месяцев. В аргументе ПС указана первоначальная сумма кредита.

Полученное значение означает, что для погашения такого кредита необходимо ежемесячно выплачивать 19343 руб. (знак «минус» показывает направление движения денежных средств и означает отток денег).

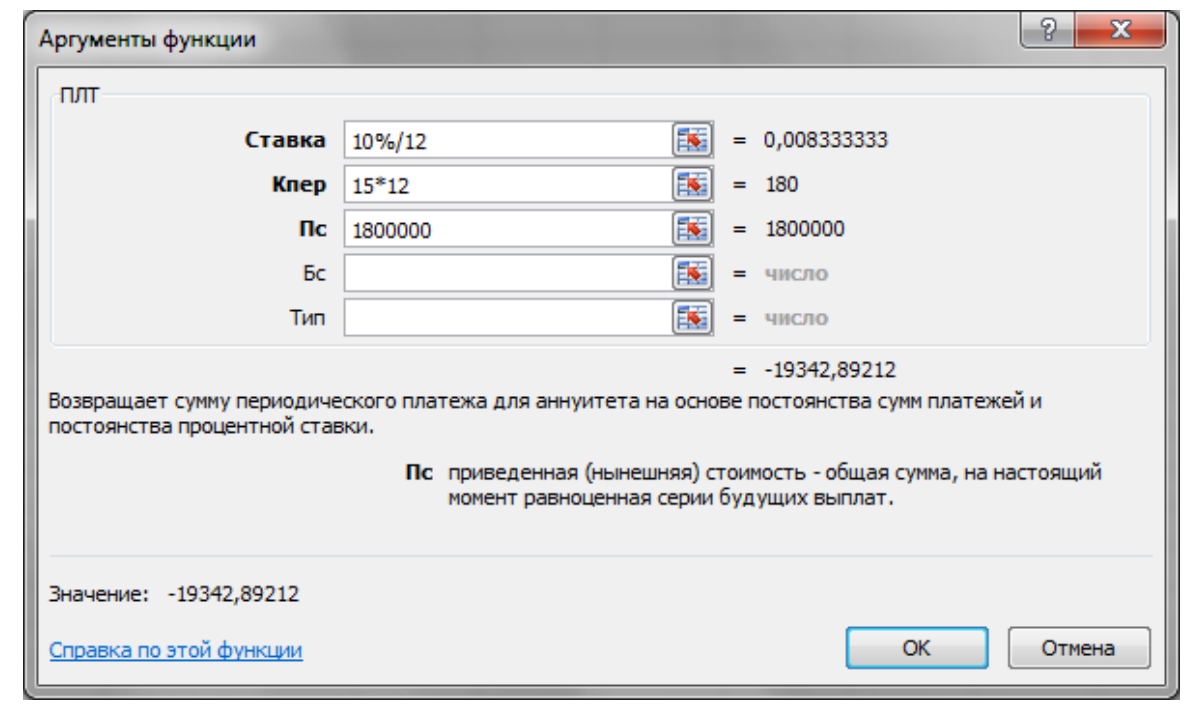

\section{Рисунок 3 - Расчет величины ежемесячного платежа по ипотечному кредиту в Microsoft Excel}

Итак, если рассмотреть семью из двух работающих человек с доходом 29874 руб. в месяц у каждого и вычесть стоимость ежемесячного платежа по ипотеке, то остаток средств составит: $29874 \times 2-19343=40405$ руб.

Из этой суммы необходимо вычесть стоимость аренды жилья, где семья проживает в настоящее время (по данным сайта недвижимости RegionalRealty.ru [11] - в среднем 14750 руб. в месяц) и оплату коммунальных услуг - 2500 руб. в месяц. В этом случае остаток денежных средств на проживание и питание на каждого члена семьи составит:

$(40405-14750-2500) / 2=11577$ руб.,

что лишь на 436 руб. больше прожиточного минимума (11141 руб.), установленного для трудоспособного населения приказом Министерства труда и социального развития Краснодарского края от 31.07.2017 № 1096 [12].

Таким образом, уже сейчас (в условиях снижения ставок по ипотеке) среднестатистическая семья с трудом может позволить себе выплачивать ипотечный кредит за однокомнатную квартиру.
При этом следует отметить, что жить на прожиточный минимум (на грани бедности) семье необходимо будет в течение 2-3 лет, на протяжении которых будет строиться их жилье. А если учитывать рост цен на продукты, одежду, платные услуги (в первом полугодии 2017 г. по данным Министерства экономики Краснодарского края он составил 5,8 \%) и вероятное продолжение снижения реальных денежных доходов (в первом полугодии 2017 г. они снизились на 3,2 \%), то можно утверждать, что эта семья будет испытывать постоянную нехватку денег. Кроме того, в расчетах использовались минимальные цены и предусматривалось отсутствие у семьи детей в течение этого времени. Отметим также, что в нашем примере расчет велся уже по сниженной до $10 \%$ ставке ипотечного кредита.

Сходные исследования провели аналитики Национального бюро кредитных историй. По их данным рекомендованный семейный доход заемщиков по ипотечному кредитованию в Краснодарском крае на 1 августа 2017 г. составил 62,3 тыс. руб. При этом за 7 месяцев 2017 г. он 
снизился на 2,3 \% (32 место в России) [13]. Данный показатель является индикатором доступности ипотечного кредитования для населения и характеризует предельное отношение ежемесячных платежей семьи по кредиту к ее ежемесячным доходам. Рассчитанный аналитиками Национального бюро кредитных историй показатель свидетельствует о том, что соотношение ежемесячных платежей к ежемесячным доходам должно быть не ниже чем «1 к $3 »$.

Помимо проведенных расчетов следует сопоставить величину снижения реальных располагаемых доходов населения с уменьшением величины ежемесячного платежа по ипотеке в результате произошедшего снижения процентных ставок.

По данным Агентства ипотечного жилищного кредитования по состоянию на январь 2017 г. средняя ставка по ипотечным кредитам составляла 11,4 \% и к июлю 2017 г. снизилась до $10,1 \%$ [5].

Воспользовавшись данными о стоимости квартиры и сроке ипотечного кредита из нашего примера, рассчитаем суммы ежемесячных платежей по кредиту с помощью финансовой функции ПЛТ Microsoft Excel:

1) при ставке 11,4 \% - 20913 руб. в месяц;

2) при ставке 10,1\% - 19453 руб. в месяц.

Разница между этими вариантами (экономия от снижения процентной ставки) составляет 1460 руб.

По данным Министерства экономики Краснодарского края за этот же период (первое полугодие 2017 г.) реальные располагаемые денежные доходы населения снизились на 3,2 \% и составили 29874 руб. [2]. Таким образом, снижение доходов составило в среднем 988 руб. в месяц.

Очевидно, что на данном этапе сокращение денежных доходов (988 руб.) меньше, чем экономия от снижения процентных ставок по ипотеке (1460 руб.), что, безусловно, стимулирует рост рынка ипотечного кредитования. Однако, как уже говорилось, резервы дальнейшего снижения ставок по ипотеке практически исчерпаны и не следует ожидать роста «экономии» от уплаты процентов, в то время как аналитики прогнозируют дальнейшее снижение доходов населения.

Приведенные данные наглядно демонстрируют, что снижение процентной ставки по ипотеке не может выступать долговременным гарантом стабильности рынка жилья.

В условиях, когда банки не смогут увеличивать количество клиентов за счет дальнейшего «удешевления» кредитов, при продолжающемся снижении реальных располагаемых денежных доходов населения и росте цен на жилье, ситуация на рынке недвижимости продолжит ухудшаться и объем вводимого жилья будет снижаться. Расчет представителей строительной отрасли на ипотеку как единственный «двигатель торговли» ведет в тупик. Хотя в настоящее время и является одним из самых эффективных механизмов стимулирования рынка жилья.

Во избежание дальнейшего падения рынка, которое продолжится после окончания времени «отсрочки», которую получила отрасль за счет действия ипотечных механизмов, необходима разработка мер по стабилизации и улучшению ситуации на рынке жилья. Наиболее очевидными условиями развития рынка в перспективе являются:

1) снижение стоимости жилья;

2) увеличение реальных денежных доходов населения.

На рост доходов населения оказывают сильное влияние внешние для отрасли факторы. Он напрямую зависит от состояния экономики региона и страны в целом, которые под влиянием зарубежных санкций демонстрируют негативную тенденцию, преодоление которой возможно путем коренных институциональных изменений в структуре экономики России, активной поддержки и развития собственного производства.

Достижение же первого условия (снижение стоимости квадратного метра жилья) возможно за счет оптимизации внутренних бизнес-процессов застройщиков и представляется вполне осуществимым.

Рассматривая этот фактор нельзя не отметить, что его реализация может быть затруднена последними изменениями законодательства. Как известно, большая часть жилой недвижимости строится путем заключения договоров долевого участия в строительстве многоквартирных домов, регулируемых федеральным законом от 30.12.2004 № 214-Ф3 «Об участии в долевом строительстве многоквартирных домов и иных объектов недвижимости и о внесении изменений в некоторые законодательные акты Российской Федерации» [14].

В июле 2017 г. в закон были внесены изменения, которые помимо регулирования размера уставного капитала строительных фирм и создания компенсационного фонда, предусматривают изменения порядка расчета строительных организаций с участниками долевого строительства (статья 15.4).

В частности, если застройщик привлекает для строительства многоквартирных домов или иных объектов недвижимости целевой кредит у кредитной организации, то участники долевого строительства будут вносить средства по 
договору (стоимость квартиры) не на счет самого застройщика, а в банк, который его кредитует, на счета эскроу. При этом доступа к этим денежным средствам у застройщика не будет до момента передачи жилья участнику долевого строительства [14].

Таким образом, строительство будет вестись застройщиком за счет собственных или заемных средств, а не за счет средств дольщиков, как это было до внесения изменений в закон. Только после окончания строительства застройщик получит доступ к денежным средствам дольщиков на счетах эскроу и сможет за их счет погашать ранее взятый в банке кредит.

Безусловно, что данная мера направлена на повышение защиты прав участников долевого строительства, чтобы ограничить возможности застройщика исчезнуть с деньгами дольщиков. Однако она не гарантирует, что банк, получивший эти денежные средства, не обанкротится или «не исчезнет».
Другая опасность данной меры состоит в возможном увеличении цен на жилье. Это может произойти в результате «двойного» использования банками средств дольщиков. Так, по новому порядку расчетов банк выдает застройщику кредит, получает на счет эскроу средства дольщиков и может этими средствами (которые формально принадлежат застройщику, т. к. вносятся дольщиками в счет его работ) снова кредитовать застройщика. Получается, что банки могут кредитовать застройщика принадлежащими ему же средствами. Такой порядок расчетов увеличивает расходы строительной организации и может вызвать рост цен на жилье.

\section{Conclusion}

Таким образом, несмотря на негативные тенденции на рынке жилья, его участники не готовы к решению стоящих перед ними проблем и ограничиваются временными полумерами.

\section{References:}

1. (2016) Ob itogah social'no-jekonomicheskogo razvitija Krasnodarskogo kraja v 2016 godu: doklad Ministerstva jekonomiki Krasnodarskogo kraja [Jelektronnyj resurs]. Available:

http://economy.krasnodar.ru/macroeconomics/a naliz/monitoring/files/d-12-2016-

\%D0\%A1.docx (Accessed: 10.09.2017).

2. (2017) Ob itogah social'no-jekonomicheskogo razvitija Krasnodarskogo kraja $\mathrm{v}$ pervom polugodii 2017 goda: doklad Ministerstva jekonomiki Krasnodarskogo kraja [Jelektronnyj resurs]. $\quad-\quad$ Available: http://economy.krasnodar.ru/macroeconomics/a naliz/monitoring/files/d-06-2017-

\%D0\%A1.docx (Accessed: 10.09.2017).

3. (2017) Ob itogah social'no-jekonomicheskogo razvitija Krasnodarskogo kraja $\mathrm{v}$ pervom kvartale 2017 goda: doklad Ministerstva jekonomiki Krasnodarskogo kraja [Jelektronnyj resurs]. Available: http://economy.krasnodar.ru/macroeconomics/a naliz/monitoring/files/d-03-2017-C.docx

(Accessed: 10.09.2017).

4. (2017) Krasnodarskij kraj v cifrah. 2016: Stat. sb. / Krasnodarstat - Krasnodar, 2017. - 327 p.

5. (2017) Itogi razvitija rynka ipoteki v 1 polugodii 2017 g.: minimal'nye stavki - rekordnye ob\#emy: analiticheskij obzor AO «AIZhK» [Jelektronnyj resurs]. - Available: https://дом.pф/wp-

content/uploads/2017/08/Itogi-razvitiya-rynkaipoteki-v-pervom-polugodii-2017-g.pdf

6. (2017) Ob\#emy vydachi ipoteki v ijule $2017 \mathrm{~g}$. vyrosli na $40 \%$, a stavki po ipotechnym kreditam dostigli istoricheskogo minimuma: analiticheskij obzor AO «AIZhK» [Jelektronnyj resurs]. - Available: https://дом.pф/wpcontent/uploads/2017/09/20170907_Spravka_o _razvitii-rynka-ipotechnogo-kreditovaniya.pdf (Accessed: 10.09.2017).

7. (2017) NBKI: situacija s prosrochennoj zadolzhennost'ju blizka k stabilizacii [Jelektronnyj resurs]. - Available: https://www.nbki.ru/company/news/?id=20823 \&sphrase_id=90680 (Accessed: 10.09.2017).

8. (2017) Analiz rynka nedvizhimosti v gorode Krasnodar, Krasnodarskij kraj [Jelektronnyj resurs]. $\quad$ - $\quad$ Available: http://www.rlt24.com/prices/krasnodar (Accessed: 10.09.2017).

9. (2017) Na Kubani v 2017g. upala dolja ipoteki na pervichnom rynke nedvizhimosti [Jelektronnyj resurs]. - Available: http://www.rbc.ru/krasnodar/freenews/5996f3e9 9a7947aa240ad5f9 (Accessed: 10.09.2017). 


\begin{tabular}{|c|c|c|c|c|c|c|}
\hline Impact Factor: & $\begin{array}{l}\text { ISRA (India) } \\
\text { ISI (Dubai, UAE } \\
\text { GIF (Australia) } \\
\text { JIF }\end{array}$ & $\begin{array}{l}=1.344 \\
=0.829 \\
=0.564 \\
=1.500\end{array}$ & $\begin{array}{l}\text { SIS (USA) } \\
\text { PИНЦ (Russia) } \\
\text { ESJI (KZ) } \\
\text { SJIF (Morocco) }\end{array}$ & $\begin{array}{l}=0.912 \\
=\mathbf{0 . 2 0 7} \\
=\mathbf{3 . 8 6 0} \\
=\mathbf{2 . 0 3 1}\end{array}$ & $\begin{array}{l}\text { ICV (Poland) } \\
\text { PIF (India) } \\
\text { IBI (India) }\end{array}$ & $\begin{array}{l}=6.630 \\
=1.940 \\
=4.260\end{array}$ \\
\hline
\end{tabular}

10. Poljakov V.E. (2016) Komp'juternye tehnologii investicionnogo analiza: ucheb. posobie / V. E. Poljakov, A. S. Kravchenko. - Krasnodar: KubGAU, 2016. - 180 p.

11. (2017) Ceny na nedvizhimost' v Krasnodare [Jelektronnyj resurs]. - Available: https://regionalrealty.ru/krasnodar/stats (Accessed: 10.09.2017).

12. $\mathrm{O}$ velichine prozhitochnogo minimuma $\mathrm{v}$ Krasnodarskom krae za 2 kvartal 2017 goda: prikaz Ministerstva truda i social'nogo razvitija Krasnodarskogo kraja ot 31.07.2017 № 1096 // Oficial'nyj sajt administracii Krasnodarskogo kraja: $\quad$ http://admkrai.krasnodar.ru (Accessed: 10.09.2017).
13. NBKI: v 2017 godu ipoteka stala dostupnee [Jelektronnyj resurs]. - Available: https://www.nbki.ru/press/pressrelease/?id=215 09 (Accessed: 10.09.2017).

14. $\overline{\mathrm{Ob}}$ uchastii $\mathrm{v}$ dolevom stroitel'stve mnogokvartirnyh domov i inyh ob\#ektov nedvizhimosti i o vnesenii izmenenij $v$ nekotorye zakonodatel'nye akty Rossijskoj Federacii: federal'nyj zakon ot 30.12.2004 № 214-FZ // Spravochno-pravovaja sistema «Konsul'tant Pljus»: [Jelektronnyj resurs] 